\title{
Profiling analysts and actors in interaction: how behavioural aspects can positively affect the decision aid process
}

\section{Maria Franca Norese ${ }^{1}$ D}

Received: 28 November 2018 / Accepted: 4 August 2020 / Published online: 18 August 2020

(c) The Author(s) 2020

\begin{abstract}
The behaviour of the actors in a decision aid process is determined by different factors, all of which have an impact on the effectiveness of the process and its results. A framework, originally created to document decision aid processes and to study the reasons for backward and forward cycles in the process, has been used to comparatively analyse several multi-criteria decision aid interventions. The study has led to the identification of three basic process typologies, in relation with some organisational and processual complexities and factors which, as behavioural aspects, have the main influence on the interaction between the analysts and actors of a decision aid process. The work is a proposal for the behavioral OR research agenda.
\end{abstract}

Keywords Decision aid process $\cdot$ Complexity factors $\cdot$ Behavioural aspects $\cdot$ Multicriteria decision aiding

\section{Introduction}

It is commonly accepted that traditional Operation Research (OR) originally focused on the scientific method to maintain objectivity... The aim was to use both the method and models to identify an optimal solution to problems, independent of perceptions, appreciations and the feelings of human beings (White 2016).

The necessity of opening the mind of operational researchers to behavioural considerations that improve the OR practice is the clear meaning behind White's message, which underlines how literature has criticised the OR original assumptions, above all in the contexts of Problem Structuring Methods (see, for instance, Rosenhead and Mingers 2001; Smith and Shaw 2019). Multi-Criteria Decision Aiding (MCDA) has also shaped the relationships between behaviour and OR. MCDA is

Maria Franca Norese

maria.norese@polito.it

$1 \quad$ Politecnico di Torino, Torino, Italy 
defined as the activity of a person who, through the use of explicit but not necessarily completely formalised models, helps obtain elements of responses to the questions posed by a stakeholder of a decision process. These elements work towards clarifying the decision and usually towards recommending, or simply favouring, behaviour that will increase the consistency between the evolution of the process and this stakeholder's objectives and value system (cf Definition 2.2, Roy 1996).

I am an experienced MCDA analyst and I have often tried to explain to my students how an analyst should behave in complex situations, but I quickly realized that this kind of knowledge is not easy to transfer (Ackermann, 2011). When my students are involved in internships and work on processes that require analysis and improvements, they are expected to document their activities as well as the rationale behind their choices and actions. In general, however, they tend to only describe the technical tools that they used and the quantitative results of their interventions.

I often meet some of my ex-students, young management engineers and sometimes actors in decision processes, who occasionally activate a decision aiding process. However, they do not know why some of their decision aid activities are effective in some situations but generate confusion and delays in others. They do not know which factors influence their behaviour, but they are aware that different decision processes and organisations require different behaviours.

Learning from past interventions is difficult without a logical framework that facilitates the analysis of how a context and its perception have oriented an action and why models and methods are tools that sometimes produce a solution that is often only the first step of the nonlinear path of decision aiding. Indeed, MCDA (see Roy and Vanderpooten 1996 and the web site of the EURO Working Group MCDA https://www.cs.put.poznan.pl/ewgmeda/) adopts a constructivist approach, where the model as constructed, the concepts and the procedures constitute a communication and reflection tool that allows the participants in the decision process to carry forward a process of thinking and to talk about the problem (Genard and Pirlot 2002). The decision aid analyst has to stimulate, orient and monitor the dynamics of this process.

In this paper, a methodological framework is proposed for MCDA analysts. It is meant to help them identify the factors that influenced their behaviour the most in their interventions, to enhance the analyst's personal experience (individual learning process) and to support knowledge sharing, as well as lessons learned for best practices among analysts, experienced and novice.

The framework is also proposed to document and collectively analyse the decision aid activities and their logics as they pertain namely to the nonlinear path that has produced interruptions, conflicts and misunderstandings, and improved and facilitated communications, reflections, and shared vision (organizational learning process in the decision process).

The main components of the framework proposed here (contexts of action and activities) were identified several years ago (Norese and Ostanello 1989), in relation to the literature proposals the first section describes. Their usability was tested and improved in several MCDA interventions in the following years. A map, a visualisation tool that synthesises the path of an analyst in a decision aid (DA) process and the prevailing nature of activities and interactions between the involved actors, was 
then introduced to complete the framework and allow it to be applied to several new MCDA interventions in public and private organisations and some recurring situations of interaction between analyst and actors to be inductively identified and associated with DA process typologies.

The second section proposes an overview of relevant literature on decision and decision aiding processes, as a terrain for the elaboration of the main framework components and their definition and use to represent a DA process as a profile in a map. The third section describes the methodological framework and the main factors that distinguish the situations, while the fourth proposes three basic typologies of a DA process, based on real previous cases. The typologies are formulated as visual representations of the analysts' paths in their MCDA interventions.

Certain elements of the expertise that has been acquired, from direct experiences with DA in different problems and organisations, are proposed in the conclusions, together with a project of experienced and novice DA analysts' involvement in future research perspectives.

\section{Stimuli from the literature on the description of a decision aid process}

In the eighties, Anna Ostanello and I made several DA interventions using a multicriteria (MC) approach that "connects the possibility of using MC methods with a specific way of acting on representations" (de Montgolfier and Bertier 1978) of a different nature and formalisation level (verbal descriptions, images or data; ideas, assertions, proposals, suspects, protests or judgements). The potentialities of this approach became particularly evident in some long and complex interventions, and underlined the central role of actions, such as structuring and communication, that are normally neglected in traditional OR (Rosenhead 2006).

We were particularly interested in the interactions between MCDA analysts and their clients, the decision-makers, and in the role of MC models and methods in practice, in complex interventions. We found a specific paper, which was the first that tried to analyse the MCDA process, particularly stimulating. It proposed a framework to synthesise the main concepts and, above all, some "decision aid mechanisms" (research, re-initialisation, reaction) which, although generated in the multi-objective optimisation field, were generalised by Bernard Roy in relation to any decision aid intervention (Roy 1976, see pp. 25-26). Another important stimulus was an analysis of the decision process and its complexity from the point of view of a facilitator (Jacquet-Lagreze et al. 1978), which was the result of the authors' analysis of a report (Witte 1972) about 233 decision processes in Germany involving the acquisition of data processing equipment.

The logical description of an OR intervention as a nonlinear and cyclic sequence of modelling and validation activities, proposed in (Landry et al 1983), together with the distinction between conceptual and formal modelling, and between their different validation needs and procedures, was very useful because it allowed us to start identifying and distinguishing the nature of our activities in a DA process. 
The basic concepts underlying the methodological research presented here are included in the structure of the "unstructured" strategic decisions proposed in (Mintzberg et al 1976). The strategic decision process, which is described as characterised by novelty, complexity, and openendedness, and by the fact that the organisation usually begins with little understanding of the decision situation it faces or the route to its solution, and has only a vague idea of what that solution might be and how it will be evaluated when it is developed (see p. 250), corresponds precisely to our perception of an MCDA intervention in complex situations. The basic structure proposed in (Mintzberg et al 1976) includes three phases (Identification, Development and Selection) of the decision process, which have different names but recall Simon's intelligence-design-choice model (Simon 1960, 1991), seven central routines, three sets of supporting routines and six sets of dynamic factors.

We adopted Mintzberg's structure to describe our "unstructured" DA interventions. The concepts of phases and central routines provided a valuable contribution and facilitated the documentation and the analysis of each intervention, and above all of its comprehension and failure cycles (two dynamic factors of the structure). We found the supporting routines of decision control and communication very interesting, although their operational use was not so straightforward.

We studied sixteen different MCDA interventions we had conducted in the eighties and we then proposed the nature and role of the main activities in (Norese and Ostanello 1989; Ostanello 1990) to document the steps of a DA process and to study the reasons behind backward and forward cycles, the elements that had forced us to backtrack to previous activities or to change elements of the model or of our understanding of the problem. The basic structure proposed in (Mintzberg et al 1976), together with the modelling and validation process proposed in (Landry et al 1983), influenced our identification of the main components of a general framework of a DA process to a great extent.

Since the 1990s, the literature on strategic decision problems has revealed interesting analyses, such as "tactics of solution identification" (Nutt 1993) and "new models of organisational decision making" (Langley et al 1995) in which sequences of minor decisions are combined differently.

Important contributions in the MCDA field (above all Roy 1996; Bouyssou et al 2000; Belton and Pictet 2002; Belton and Stewart 2002; Genard and Pirlot 2002 and Vanderpooten 2002) stimulated reflexions on the DA process and Tsoukias (2007) arrived at the conclusion that a decision aid process is a particular type of decision process. He described some possible different approaches to conducting a DA process and introduced the definition of the DA process as a distributed cognition process.

In the same years, the use of problem structuring methods (Rosenhead 1996; Rosenhead and Mingers 2001) expanded and disseminated the idea that a common space of interpretation and understanding has to be created in a DA process to structure the analysed system and elaborate a clear problem formulation. Specific MC procedures were proposed to answer the same needs and were oriented towards understanding complex situations and organising models consistent with the identified complexities (Norese 1996; Ostanello 1996). 
Since the 1990s, each DA intervention that I have dealt with, in relation to different problems, has become the subject of study during the intervention and in the ex-post analysis, to test the validity of the identified components of the DA process presented here, in relation to new stimuli from literature (see, for instance, Franco and Montibeller 2010; Marttunen et al 2017; Ormerod 2018; Colorni and Tsoukiàs 2018) and the experience of other DA analysts.

\section{A methodological framework of the interaction process between analysts and actors in MCDA}

The methodological proposals from literature and the ex-post analysis of some personal MCDA cases allowed the first steps to be made towards the elaboration of a general framework of a decision aid process. The first results were the identification of the main components (contexts of action and activities) of the framework and the creation of a map to profile the analyst in interaction with the decision-makers, actors and information and knowledge sources. These elements are described in Sects. 3.1 and 3.2.

I then used these methodological tools in every new DA intervention to extensively document the work and to identify any possible factors that could have an important impact on the decision aid processes and their results, and to analyse them as behavioural aspects that could affect the interactions between the analysts and actors in the decision aid processes. I recognised some recurring situations and I tried to associate specific elements of complexity and behaviour with these situations, to identify certain DA process typologies, which are presented hereafter in Sect. 4.

\subsection{Contexts of action and activities in a decision aiding process}

A DA process deals with a decision problem, in relation to a phase (or more than one) of a decision process (Simon 1960, 1991) and a decision system, i.e. decisionmakers and actors involved in a decision process and a decision structure that is formalized to some extent (actors' roles recognized by the involved organizations and specific rules to be implemented in the process, such as number and nature of formal and informal meetings; verbalization need, task and space of action of a facilitator and/or a coordinator; formal relationships with non-directly involved actors or actors in related decision processes etc.).

The decision problem should be sufficiently clear and structured when the decision process arrives at the Choice phase, and any technical action should, therefore, be clearly defined, while the information and knowledge resources should at least be accessible. Therefore, the complexity of the decision process should be limited. However, the need for a DA intervention result may be urgent, and acquiring sufficient knowledge of the previous phases and steps of the decision process may require time and the understanding of a long sequence of past 
internal or external actions (above all when several actors are involved at an individual or organisational level).

When the decision process is in the Intelligence phase, that is, an initial predecisional state that is mainly oriented towards understanding and analysis, the problem can be completely new, with a severe lack of knowledge, and a decision system has often not yet been activated. These criticalities may be compensated for by adopting not very restricted time limits because a decision is not imminent.

The complexity and uncertainty elements of the situation determine the nature of the DA process and, therefore, the activities that have to be implemented and their sequence. Several factors can guide an analyst towards a specific DA approach. The state of development and evolution of the decision process should be identified at the start of each DA process. The other main factors are:

- the organisational complexity (the number of individual and organisational participants and their roles and relationships in the decision process; the nature and structure of the decision system and its involvement in the DA process; the cooperative or conflictual context, and so on) and

- the operational complexity, above all the structuring level of the problem situation, the multiplicity and interdependency level of the problem issues, as they are analysed in (Friend 1989), and the resource state, with reference in particular to the time and to the availability and reliability of the data, information and knowledge.

A decision aid intervention can rarely be described as a linear process. Real problem situations induce DA processes that are characterised by recurring cycles (see Belton and Stewart 2002) which generally cause delays and lead to a difficult way of proceeding. However, these cycles allow the analyst to capture the complexity that is always present in real life, to acquire and process information, to identify and control uncertainty, to activate, if required, revisions of problem formulation or structuring and/or model building.

Eight DA sub-processes were identified, each one with different expected results, and were defined as contexts of action (Norese and Ostanello 1989). They are characterised by a specific domain of application of the activities and by the use of specific tools, whose purposes can be cognitive or operational, and sometimes political-organisational. Two of them, Identification and Development, recall the names and contents of the first and second phases of Mintzberg's model (Mintzberg et al 1976) and their routines. Control is another context, which is sometimes oriented towards controlling the DA process, but in general includes the verification and validation activities of the process (as proposed in Landry et al 1983). We called the last context of action Structuring, because our interventions, in relation to complex and new decision problems, had been oriented more to structuring information and elements of knowledge than to developing solutions. Later on, the book by Rosenhead (1989) offered us precious confirmation of our perception.

The main aims and application domains of the first contexts of action are: 
Identification (Id) of the nature and complexity of the decision problem, and of the organisational ambit that perceives or has to deal with the decision problem, of the possible operational approaches, of the information and knowledge elements that are significant for the specific decision situation, which are at least partially available or they all need to be acquired, and of the uncertainty that is associated with these elements;

Structuring (Str) of the decision problem, the identified information and knowledge elements, the operational approach and models, before they are developed in a formal way;

Development (Dev), in a formal way, of a possible course of action or a procedure, a knowledge base or an information base, a model, with its components and possible scenarios, an application of a method or an analysis of its results; Control (Ctr), which includes DA process management, uncertainty control, evaluation, quality control of each partial or overall, final or temporary DA result of a cognitive/operational or organisational/communicative nature, expost evaluations.

An analyst can activate one of the contexts, either working at an individual level (mainly concerning formal modelling, method applications, result analysis and validation of each conceptual and analytical modelling result) or in relation to different Communication situations between a problem owner/client and an analyst, but also between an analyst and the actors in the decision process. In these situations, the analyst's behaviour becomes mainly relational. These new contexts of action are defined as Communication for Identification (Com/Id), Communication for Structuring (Com/Str), Communication for Control (Com/Ctr) and Communication for Development (Com/Dev), and specific representation schemes are used to facilitate inquiry, diffuse information, explain, clarify, justify, persuade, negotiate and to acquire consensus and legitimation.

Each individual or interactive context of action is associated with elementary activities or procedures (i.e. structured sequences of activities) that make the purpose of the context of action operational. A complete list of all the activities is not possible, but in (Norese and Ostanello 1989) we grouped them into five types as the four technical contexts of actions plus communication, which synthesises the set of interactive contexts of action, to simplify their memorisation and the analysis of their meaning in a specific context.

Each type is associated with a code (Ri), and some examples of the possible activities of each type are indicated in brackets after the code and name of each activity type:

R1-identification (examining, exploring, seeking, diagnosing, recognising, distinguishing),

R2-structuring (shaping a decision problem, organisation of knowledge/information elements, the sequencing of activities, the act of arranging elements of uncertainty, ambiguity and contradiction),

R3-control (testing, verification, validation, evaluation, impasse or conflict management, uncertainty control, choosing), 
R4-development (shaping, elaboration, creation, modelling, design, planning, processing, applying, activating),

R5-communication (explanation, clarification, informing, calling attention to, facilitating cooperation, coordination, stimulating new and shared representations, a debate or explicit points of view).

A context of action can be associated with different activities: usually with the activity of the same name, but other activities can contribute towards making the purpose of the context operational. For example, organising and improving a knowledge base for a DA intervention is the aim of one of the specific contexts of action, Structuring. A sequence of several activities allows this aim to be achieved: an activity of new knowledge source identification and knowledge acquisition (R1), followed by a verification activity of the knowledge reliability (R3) and by others that organise the connections between old and new elements (R2). At this time, previous knowledge elements are validated (R3), because they seem to be linked to the new elements and are confirmed by the new source, or possible contradictions are identified (R1) and used to acquire and structure new knowledge elements (R1 and R2).

Some activities, which are put into action in the Control or Com/Ctr contexts, determine whether the DA process can move forward, or should go backward, to re-activate previous contexts of action or to switch to other more promising actions. Any passage from one context of action to another is the consequence of the expected result validation activities, which demonstrate whether the predefined purposes have been partially or totally attained, or if they are unreachable and a different technical approach is, therefore, required.

\subsection{A map to profile the analyst's behaviour in a decision aid process}

A real-life DA process is not often described in detail in literature and the DA actors' behaviour is not always analysed and described in terms that are sufficiently clear, especially when the DA process has to be understood by an audience that consists of students or non-expert practitioners (Ormerod 2014). Therefore, a visualisation tool was created and used to profile the analyst's behaviour and the interactions with and between the actors in the DA processes and to facilitate the understanding and communication of past experiences. This tool consists of a grid where any activated context of action (and its purpose) is described by means of its required activities and procedures, to make the meaning of each individual or collective activity and the aim of each associated tool explicit. The grid is divided into four quarters to distinguish four organisational situations during a DA process and two different analysts' behaviours, one mainly technical and the other mainly relational (see Fig. 1).

The grid rows are associated with the contexts of action. There are four lines in relation to the operational level (second and third quarters, Id, Str, Ctr, Dev), where an analyst is mainly focused on answering the client's demand. Another four $(\mathrm{Com} / \mathrm{Id}, \mathrm{Com} / \mathrm{Str}, \mathrm{Com} / \mathrm{Ctr}$, Com/Dev) are in relation with the analyst's interaction with the client (first quarter) or, when it is required, with the decision system and the decision process actors (fourth quarter). Each column is 


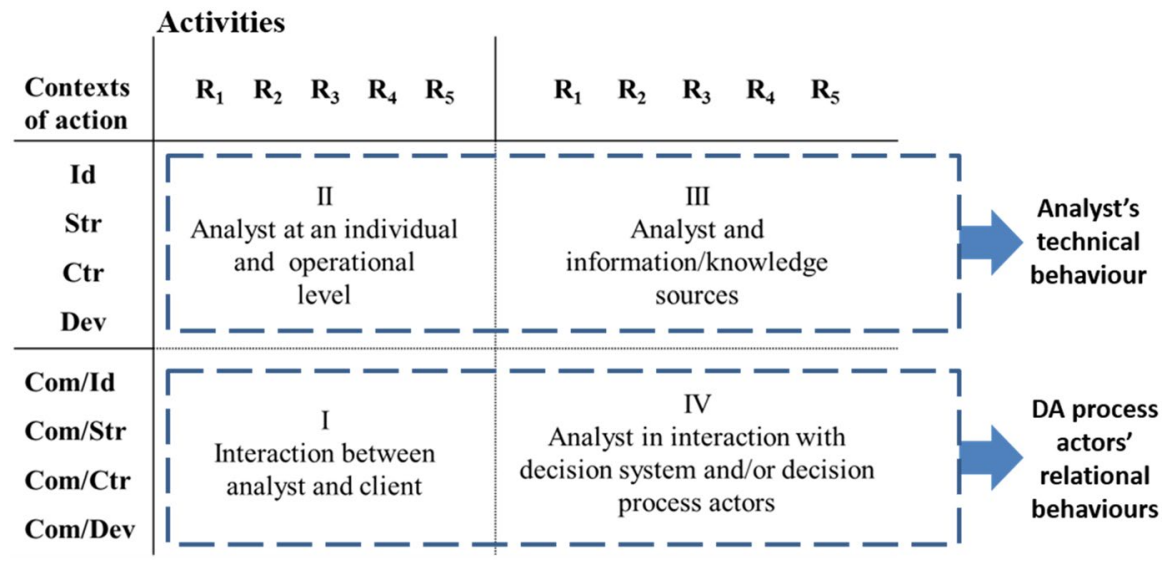

Fig. 1 A map to profile the analyst's behaviour in a DA process

associated with an activity that can be developed in a context of action, and each point of the grid is the intersection of a row and a column.

The path of an analyst during a DA process and its constituting steps can be documented as a sequence of points on a map. Each point represents an analyst's activity (as indicated by the position of a point on a column) and the context of action in which the activity is implemented (the position of the point on a row), i.e. the meaning and main purpose of the specific activity in a DA process. The line that connects this sequence of points suggests a "profile of the analyst's behaviour" during a DA process, which can fundamentally be relational (if the profile is mainly developed in the quarter(s) I (and IV) of the grid) or cognitiveoperational, if the other two quarters are used more.

The first quarter includes all the relationships between an analyst and client. Sometimes, the relationship is minimal and limited to an initial interaction, to define the problem situation and indicate the needs and available resources, and then to a final communication of the results and testing of their reliability and applicability (always in the Com/Ctr context). In other situations, the client is more involved in the DA process, and participation, therefore, implies collective $\mathrm{Com} / \mathrm{Str}$ and/or Com/Dev actions in the first quarter, and a shared control of the DA process (Com/Ctr), and not only a verification of the quality of each result.

The second and third quarters are used to document the several possible activities, associated with contexts of action, at an individual level. The operational activities are documented in the second quarter, while the cognitive, to identify knowledge sources, and to investigate and acquire data, information and knowledge, in the third quarter. The fourth quarter indicates direct and operational interactions of the analyst with the decision system and sometimes with the decision process. The involvement of the analyst in the decision system and/or in the decision process is a natural characteristic of some DA processes (the behavioural characteristics of participatory processes are described in White (2016)) or it is 
required because only the points of view and expectations of the actors and their organisations allow the analyst to define and structure the problem and model.

The map can be used to easily communicate the meaning and complexity of a specific intervention to others (students, analysts, information /knowledge sources, actors and decision-makers). It allows an easy and immediate distinction to be made between DA processes considering that, in some cases, only two quarters are used and the activities in three or four quarters are evident in other situations.

\section{Application of the profiling map to distinguish basic DA processes}

A new analysis of the old cases (a great deal of paper and electronic documents, notes, formal and informal minutes of the meetings and transparencies for workshops and conferences), plus several cases that I have dealt with since the 1990s, has verified the validity of the original definition of contexts of action and activities. Some experienced DA analysts used and are using the proposed DA components to analyse their DA interventions. It was not necessary to change anything and no new components had to be introduced. Only the list of the possible activities, in relation to the five typologies, increased.

I used the map of the DA process (see Sect. 3.2) to document, analyse and compare situations. Specific procedures, as sequences of activities in a context of action in relation to some specific situations, were identified and studied, and their graphical representations were inferred for several situations (Montagna and Norese 2008; Norese 2010, 2016b). Backward cycle sequences were studied to identify the critical factors and elements of complexity that had not been clearly recognised at the start of the DA process. The elements that can generate difficulties in a DA process should be described and their knowledge easily transferred to practitioners and young DA analysts.

A profiling map can be used to describe the main complexity factors, in the DA processes, that require specific and different DA approaches. The main elements, which are important reasons for the behaviour of the actors in the DA processes, can be analysed in relation to the organisational and/or operational factors of complexity (see Sect. 3.1) and some criticalities that are associated with the nature of a problem situation and a decision situation. Adopting Simon's three-phase framework of Intelligence, Design and Choice (Simon 1960, 1991), a possible distinction between decision situations (and, therefore, between decision aid approaches) is related to the decision process phase in which an MCDA intervention develops.

Logical representations of the different complexities of these DA processes are proposed in the map (see Fig. 2 a, b). Different quarters are used and several (vertical) shifts of the context of action are sometimes evident (e.g. data and knowledge are identified and then structured, to develop a model and then the application of a method), while a sequence of different activities in the same context (horizontal shifts) is frequent in other situations, because only an intense integration between activities, i.e. a specific procedure, can achieve the purpose of a context of action.

Figure 2a logically and synthetically represents two decision aid processes developed in the Choice phase of a decision process. The DA processes that mainly 

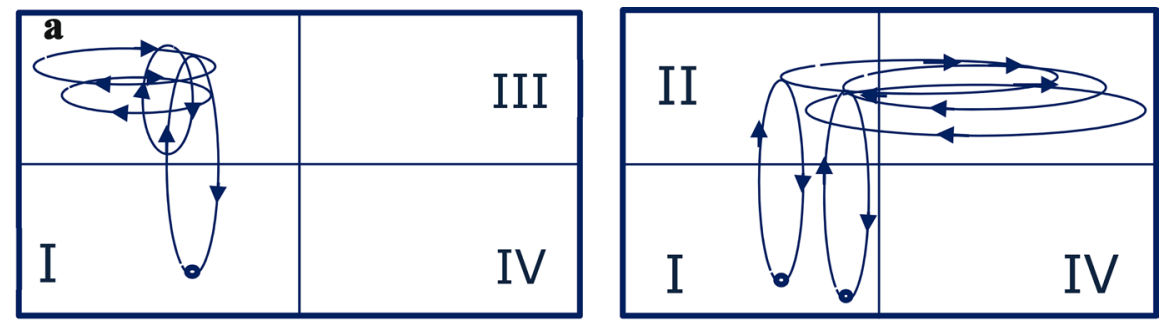

b
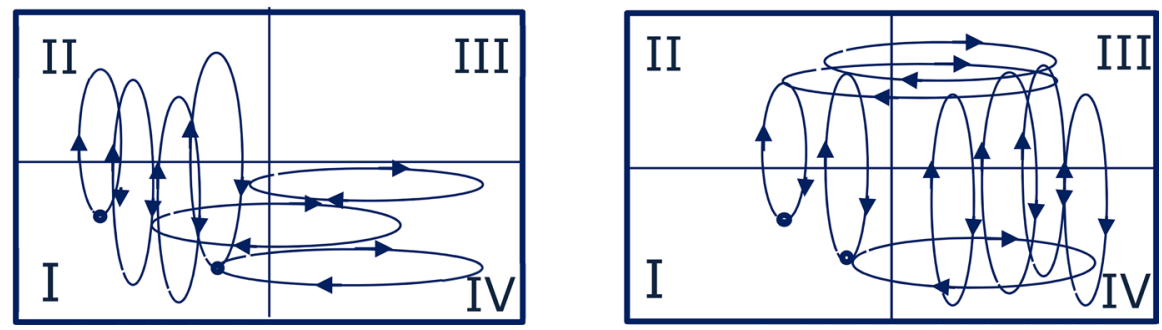

Fig. 2 a Synthetic profiles of DA processes (at least partially structured problems). b Synthetic profiles of DA processes (new problems and involvement of a decision system in a DA process)

develop in the second quarter of the map, in general, refer to a problem that is at least partially structured, while information that is consistent with the problem is present, although not immediately available, in the involved organisation(s). When knowledge and information are available and reliable at the start of the DA process, model structuring and development, and method application and result validation are activated in the second quarter, while the first quarter only includes communication between the analyst and client-oriented towards problem identification and definition $(\mathrm{Com} / \mathrm{Id})$, and then the result analysis and validation $(\mathrm{Com} / \mathrm{Ctr})$. In some situations, the third quarter also becomes important because an operational complexity is associated with the cognitive needs of the DA process, which have to be satisfied through knowledge/information sources of the involved organisation(s), in the Identification and/or Structuring contexts of action.

A DA intervention is very different if the problem is new, with a severe lack of knowledge, and the decision process is in the Intelligence phase and mainly oriented towards understanding and analysis. In these situations, a structured decision system has often not yet been activated and the client may be someone who perceives the possibility of (or the need for) activating a new decision process, or may have been an actor in a past decision process who would like to take on a more active role in relation to the future process. The operational complexity concerns the information state (data and information can be completely or partially lacking and information sources unknown), as well as an ill or non-structured decision problem. Activities in the fourth quarter of the map (see Fig. 2b) indicate that Communication contexts are activated because the DA analyst has to involve the organisation and all of the possible stakeholders, not only in information acquisition but also in problem formulation 
and structuring. Continuous shifts of contexts of action mainly indicate sequences of problem re-formulations, and different modelling/validation approaches in the second quarter, or the involvement of new knowledge sources in the third or fourth.

A specific difficulty of a DA intervention, above all for young practitioners, is the distinction between the information sources of an organisation, which facilitate the activities of an analyst in Identification, Structuring or Control contexts of action in the third quarter, and the actors in the decision process, in interaction with the analyst in the fourth quarter. Both quarters can be covered in a DA process, but the roles and activities of an analyst are technical (cognitive) in the third quarter, while they become organisational-political in the fourth quarter.

This situation is evident when a DA intervention is activated for a collective decision and the actors are directly involved in the DA process. It may be less evident when an apparent investigation becomes a direct, and sometimes unintended and not fully understood, involvement in a complex decision process.

Based on a comparative analysis of several cases of direct DA intervention (more than 30 cases that I dealt with), and of some MCDA applications that were analysed in (Norese 2016a), three typological situations, or basic DA processes, have emerged. I call these Model structuring and method application, Action development and Problem formulation. Specific versions and limited variants of these three basic situations are present in some cases, while a sequence of these basic DA processes is present in others. Each basic DA process is logically described below, in terms of its main characteristics, and a specific case is then synthetically described.

\subsection{Model structuring and method application}

This kind of DA process develops in the first and second quarters when the client's request for an intervention (starting point, in the first quarter) is clear and wellstructured and can refer to knowledge of the problem, pre-existing procedures and/ or partially structured information. All the elements that have to be included in a formal model are collectively identified in the first quarter and stated in the second (Fig. 3a). A vertical cycle, which connects two quarters, indicates an iteration between different contexts of communication (first quarter, above all Com/Id and $\mathrm{Com} / \mathrm{Ctr}$ ) and an operational use of their outputs, in the second quarter. Horizontal cycles indicate that the acquired elements are structured (Structuring context, cycle
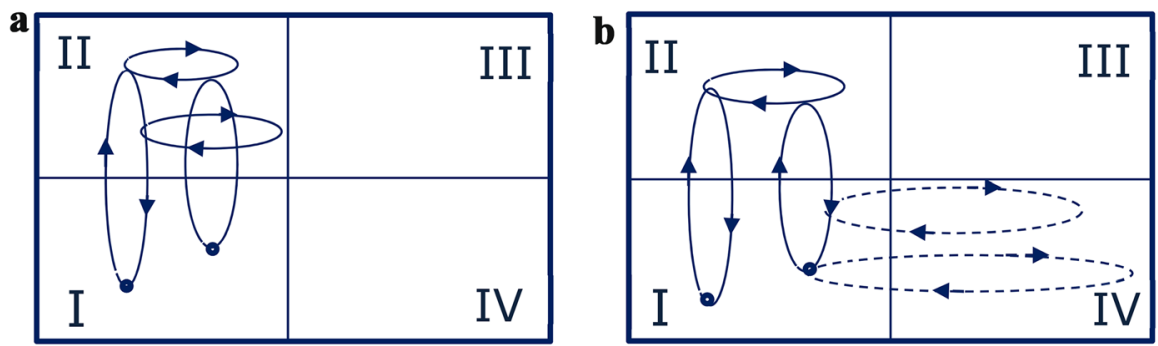

Fig. 3 a Profile of the typology. b A variant 
of the R2 and R3 activities) and formally developed in relation to a possible method application (Development context of action, the cycle of the R4 and R3 activities). When the model has been developed, a method application, a result analysis and a validation procedure are conducted, first in the second quarter (in the Development context) and then in the first quarter (in the Com/Ctr context) to conclude the DA process.

A variant of this basic DA process also implies the use of the fourth quarter, because some actors in the decision process are involved in model structuring and validation, that is, in shared activities (in this case in the fourth quarter), as far as validation of the temporary and final results are concerned. A case that corresponds to this variant was described in (Norese and Torta 2014). This situation is characterised by a cooperation of the actors who work for and together with the decision-maker. Their activities are described in the fourth quarter to distinguish them from the decision maker's activity (dotted lines in Fig. 3b), but they can be inserted directly into the first quarter because these actors are included in the decision system.

Figure 4 describes a project selection case, pertaining to the public administration (Norese and Viale 2002), as a path on the map that starts (point 1) in an essentially communicative context, oriented towards defining the intervention mode and the time limits (the Com/Str context and the R5 activity in the first quarter).

Point 2 is always communicative but is aimed at identifying elements of knowledge and information, in relation to the past procedure and its weakness $(\mathrm{Com} / \mathrm{Id}$, R5). The iterative activations of the R2 and R3 activities (cycle of points 3 and 4, in the Structuring context, second quarter) are used to structure and control the acquired elements. Another cycle of R4 and R3 activities is used to formally develop a model and some applications of a method, in relation to data from old projects, and to validate the model and method results (cycle of points 5 and 6, in the Development context, second quarter). The results are analysed and validated in the first quarter (in the Com/Ctr context, the R3 activity, point 7). After the method application to the new projects (a new R4 and R3 cycle), the DA process comes to an end.

In the studied case, when a new DA intervention was required to update the previous model, in relation to new requirements, the DA path was reproduced with the

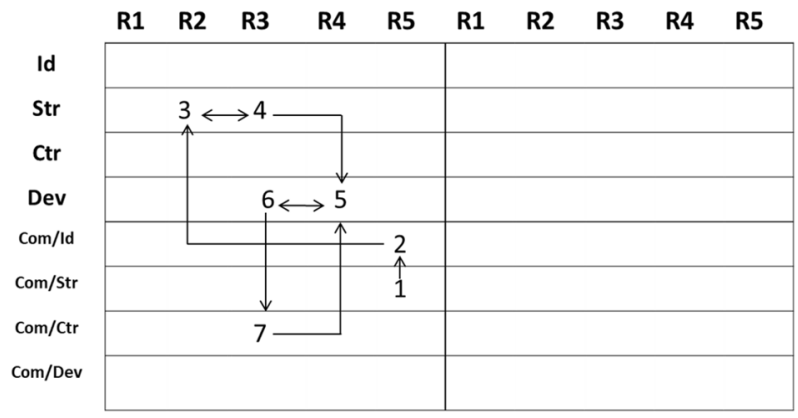

Fig. 4 An example of Model structuring and method application DA process 
same structure. The client's understanding of the path and involvement in the model updating were directed towards generating self-sufficiency in the repeated decisions concerning this course of action.

\subsection{Action development}

When the request is well structured and refers to partially structured information, but no possible solutions or alternative courses of action are available, the DA process is mainly directed towards identifying some possible actions (sometimes in the organisation memory) or towards elaborating them through a specific sequence of activities.

The term "action" here refers to Bernard Roy's definition of this general concept: "An action $a$ is the representation of a possible contribution to the comprehensive decision that can be considered autonomously with respect to the decision process development state and which can serve as an application point for decision aid. The application point is then sufficient to characterize $a$ " (Roy 1996). Moreover, a potential action is "an actual or dummy action temporarily judged as being realistic by at least one actor or assumed as being such by the analyst".

Generating potential actions is a decision problem and a component of a DA process that is underdeveloped in the literature (Colorni and Tsoukiàs 2018). Action identification and Action elaboration are here proposed as two variants of the same basic DA process, whose name refers directly to the Development phase in (Mintzberg et al 1976) and the main purpose is the development of the potential actions of an MC model to then pass on to the application of an MC method.

\subsubsection{Action identification}

Mintzberg et al (1976), analysing strategic decision processes, defined a Search and Screen Routine that moves from one activity (exploring and searching for readymade solutions) to another (screening the ones that are not consistent with the requirements), and recursively identifies and selects a new set of alternatives, until a final "stable" set of developed alternatives is reached.

In an MCDA process, Action identification means that some investigations are performed, above all in the third quarter, to explore the organisation (or the organisation environment) and identify possible actions, to evaluate them and exclude the ones that are not consistent with the requirements. This is an incremental approach because evaluation and exclusion allow the needs to be defined more clearly, in relation to the limits and potentialities of the identified actions. A new set of actions is then identified, and so on, until consistent actions are found and the system requirements are stabilised (Identification context, the cycle of R1 and R3 activities) (Fig. 5). If multiple sources of a different nature and formalisation level are involved, a Structuring context becomes essential (a cycle of R2 and R3 activities, in the second or third quarter with the aid of the sources).

Subsequently, there is a shift to a Development context in the second quarter, to develop a formal model, which includes the identified actions, and then the 
Fig. 5 Action identification

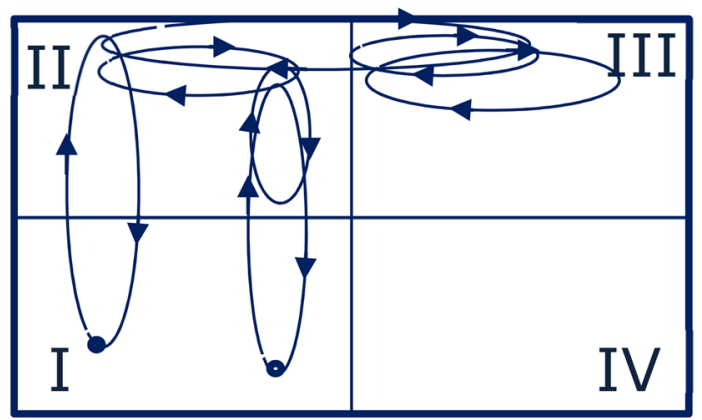

application of a method. The quality of the results is tested at the technical level (second quarter, Control context) and with the client or the decision system (first quarter, the $\mathrm{Com} / \mathrm{Ctr}$ context of action).

A specific case of this DA process was described in (Norese et al 2015). The request was clear (some companies were involved in an innovation project and wanted to know the requirements of the potential new clients) and there was partially structured information on the product (military Unmanned Aerial Vehicles-UAV that they wished to direct towards civil applications) (point 1 in the first quarter, see Fig. 6). The structuring of a possible approach started from the identification of a set of possible clients (point 2) to acquire knowledge from their needs, proposals and suggestions. In this case, the identification of possible actions (i.e. a complete list of possible civil applications) was necessary to identify the specific requirements that should have been included in the company's product improvement processes. The main part of the DA process is profiled on the map in the Identification context of action in the third quarter (points 3 and 4). The search for the possible civil UAV uses (the actions) was made by questioning the possible clients, in the Public Administration, who were not involved as actors in the decision process at this initial phase of the project. The R3 activities verified whether the identified actions were consistent with the available or possible performances of a UAV. Points 5 and 6 (Structuring context, second quarter) are associated with structuring and control activities, to create classes of actions and verify their completeness and legibility,

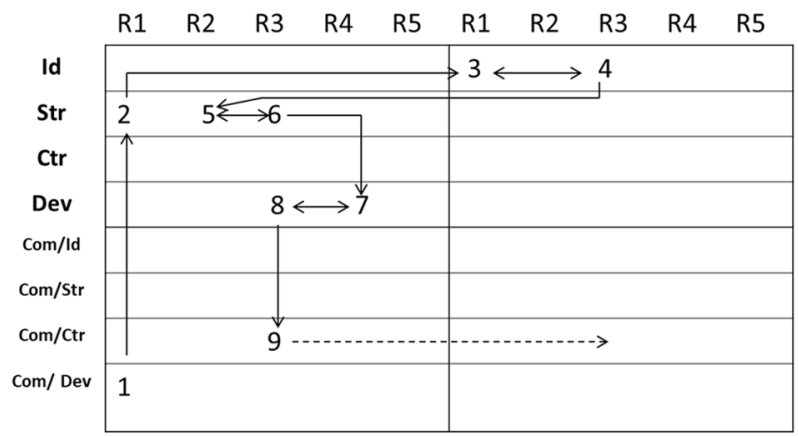

Fig. 6 A DA process of Action identification 
to develop a requirement model (points 7 and 8 in the Development context). The model was analysed with the involved companies in terms of feasibility (point 9), to propose it to new actors (the most interesting possible clients) in a future phase of the project.

\subsubsection{Action elaboration}

Mintzberg et al (1976) hypothesised that when faced with repeated failure in the search for an acceptable ready-made solution, an organisation resorts, whenever possible, to the design of a modified or custom-made solution. This is a complex and iterative procedure that begins with a vague image of an ideal solution and then goes through to a sequence of nested cycles, each narrower and more focused than the previous one. The organisation is generally oriented towards designing only one fully-developed solution because the design of custom-made solutions is expensive and time consuming, but when a limited amount of design is involved, as in modified solutions, organisations are willing to develop a second solution to compare with the first one.

In an MCDA process, when the problem situation is new and possible actions cannot be identified in the organisation and its environment, all the knowledge elements of the involved actors are used to elaborate at least one action and to modify it and produce some variants, in relation to the different points of view of the involved actors (Fig. 7).

A Communication context for the Development of complex actions (Com/Dev) has to be activated with the client (first quarter), and the action space and its complexity factors should be identified (R1 activities). The same Com/Dev context is made operational in the fourth quarter by considering activities in interaction with the decision system and decision process actors. Any element (idea, debate, inquiry, report, local rule and so on) that could be connected to the actions that have to be elaborated generates fragments of action (as defined in Roy 1996), which are combined during each iteration, if significant for the problem and reliable (cycle of interactive R2 and R3 activities). A shift to the second quarter allows these structured elements to be formally developed and their consistency to be verified (cycle of interactive R4 and R3 activities in a Development context). Other shifts from the second quarter to the fourth one and back to the

Fig. 7 Action elaboration

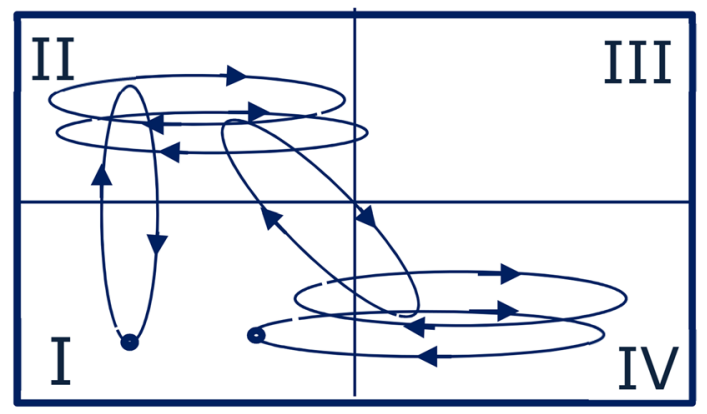


second quarter are required until a complete frame has been structured and validated. When one or more actions are elaborated, they can be evaluated and compared in the second quarter, to arrive at an acceptable result, at both a technical (second quarter, Development context) and decisional level, with the client (first quarter, the context of action Com/Ctr) or with the involved actors (fourth quarter, $\mathrm{Com} / \mathrm{Ctr}$ ).

Action elaboration is a DA process that is closely related to organisational complexity, where the roles and relationships of the participants in the decision process are crucial. Each specific activity, in a Communication context in the fourth quarter, can generate unexpected results, not only in the DA process but also in the decision process. Certain observed difficulties and real technical mistakes suggested the need for a specific tool, a model management support system that facilitates the analysis when the main complexity factor is associated with the organisation and its conflictual context, and the Multiple ACtors RepresentAtions ModElling (MACRAME, see Norese 1995; Norese and Salassa 2014) is the only possible approach of fragmented knowledge acquisition.

Concurrently, a good relationship with participants and between the participants positively impacts the operational complexity, because these actors are essential knowledge sources.

Figure 8 presents a case of Action elaboration for a public administration (Norese 1996), in relation to an innovative Emergency Department project in Regional hospitals. The points of view and improvement proposals of the actors (coordinators and personnel of emergency departments) were analysed in a shared modelling action. The components and structure of alternative possible actions were analysed in the fourth quarter (points 2 and 3, Com/Dev, cycle of R2 and R3 activities) and formal actions were then developed (points 4 and 5, cycle of R4 and R5 activities). Criteria to evaluate the generated actions were developed in the fourth quarter (points 2 and 3, Com/Dev) to be used in the second quarter in an MC method application (points 4 and 5, cycle of R4 and R5 activities).

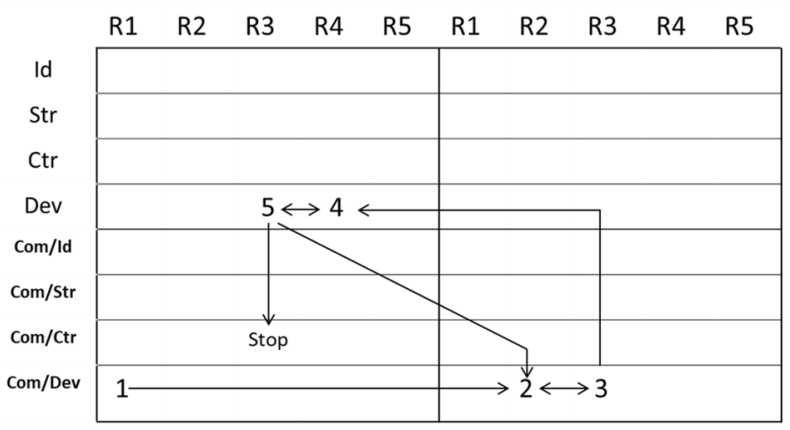

Fig. 8 An example of Action elaboration 


\subsection{Problem formulation}

A DA process may become very complex if the request is ill-structured and not clear, above all when the problem situation is new and information, knowledge and previous procedures do not exist. It is important that the problem can be seen and analysed in its total context, in order to be clarified and defined (Bowen 1983).

In these situations, a formal decision system does not often exist, because it has not yet been activated, and the client, who may be an actor in some decision processes who perceives the need for the activation of innovative situations, often involves experts to obtain a better understanding of the problem and to activate a pre-decision phase of Intelligence. The client may also be a researcher, that is, an expert in a specific domain, who becomes a DM in relation to a new and badly structured research project. An analyst may be involved as an expert in MCDA and may be included in a team of experts, or may interact with the client and facilitate the understanding of the problem and the relationships between its main components.

The collective work of analysing data and elements of knowledge and redefining them until an acceptable level of internal consistency is obtained, is aimed at formulating the decision problem and at developing schemes for present or future decisions.

At the start of a DA intervention, a problem formulation may not exist, but it can gradually evolve from a generic indication of a need to the definition of a problem situation. The DA intervention mainly develops in the fourth and second quarters, or only in the fourth when the analyst becomes an actor in the decision process (see Fig. 9).

Recurring shifts from structuring to validation, and vice versa, are adopted to organise and validate, or re-organise and test, structures of knowledge that can include and synthesise elements from different sources, and which can vary from structured data to incomplete analyses, verbal indications, interpretations and so on (Com/Str and Com/Ctr). Different activities can make the purposes of the contexts of action operational. R1 can solicit and facilitate knowledge acquisition, while R4 develops and R5 proposes formal representations to facilitate communication oriented towards structuring and control.
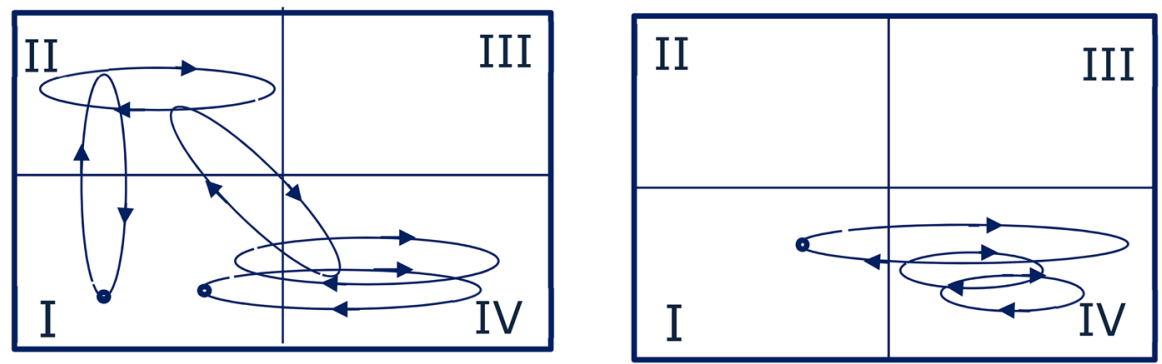

Fig. 9 Problem formulation as a basic DA process 
When some components of the problem seem structured and validated, their formalisation in a shared problem formulation (Com/Dev) requires a control context of the action that either validates the results or indicates the need for de-structuring and re-structuring (a new shift from Com/Dev to Com/Ctr and from Com/Ctr to Com/ Str, if required).

A specific version of Problem formulation is frequent in relation to innovative research projects, where an analyst and researchers interact in the fourth quarter.

\subsubsection{Model-based process (MBP) of problem formulation and model structuring}

When a problem arises in a research context that is so new that problem formulation is not an easy step, a specific version of problem formulation can be used (see Balestra et al 2001; Cavallo and Norese 2001; Norese et al 2016a, b; Norese and Scarelli 2016). A draft of a multicriteria model is structured and tested by the research team in the fourth quarter (points 2 and 3, Com/Str, cycle of R2 and R3 activities, Fig. 10) and the available data are used to develop the first application of an MC method (point 4, R4, Com/Dev). The shared analysis of the results of this application, in a Control context of action (point 5, R3, Com/Ctr), is used to identify weaknesses in the results and the possible reasons for any weakness in the model parameters or structure (point 6, R1, Com/Ctr), and, therefore, to introduce possible changes. The improvement proposals of some model parameters are then used in a cycle of method application and testing of the results (cycle 6-4-5-6). If these improvements are not sufficient, new cycles of model re-structuring, MC method application and result analysis are activated (cycle 6-2-3-4-5-6, new problem formulation). I described this structured sequence of activities in (Norese 2016b) as a specific MCDA process that is based on a new and conscious use of multicriteria models as communication spaces and I called this DA process Model-Based Process. It is oriented towards improving the robustness of a DA intervention and its results through an incremental and shared definition of the problem and model. The main aim of this process is to reduce the uncertainty that is often not only associated with the model parameters but also with the model structure when the problem

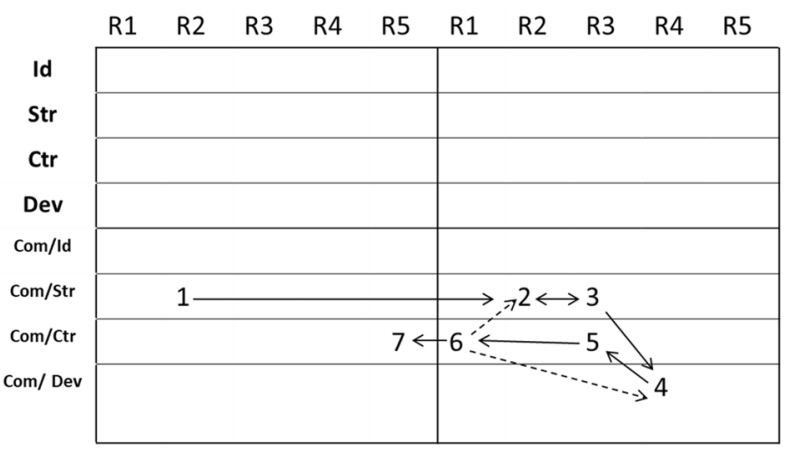

Fig. 10 An example of MBP of problem formulation and model structuring 
formulation is not clear or well defined (see, for instance, Norese et al 2013; Norese and Carbone 2014).

\subsection{A sequence of basic DA processes}

A sequence of basic DA processes is often present when a first DA approach does not produce results but leads the analyst towards another basic DA process. In other situations, a sequence of two or more basic DA processes indicates a DA process that requires more than one phase. It may start as Problem formulation and evolve towards contexts of action and activities of Action development, if the problem formulation does not include possible actions, to complete the DA intervention.

An example of both these situations was described in (Norese 2010) and proposed the behaviour of an analyst in an expert team, where communication and interaction were essential for the problem formulation (fourth quarter) and then to model structuring and development (second quarter). At the end of an innovative monitoring of projects funded in a Public Administration, the DM activated a "table of experts" to synthesise the monitoring results (point 1 in Fig. 11). The table included field experts, but also the author, as an expert in methodologies, some analysts who had monitored the development of the funded projects and a few coordinators of the funded projects.

The DM's request was considered to be too generic, then the table of experts tried to obtain indications on the purposes of the monitoring process and the possible uses of the monitoring results, but the tentative did not produce any effect. As a consequence of this DM's unstructured request, the experts conducted an analysis of the funding law, its implementation and the data from the monitoring process, which produced a debate between the experts in relation to the concepts they used to define criticisms and weaknesses. The generated conflictual ambit of work led to each attempt of problem formulation being blocked because each expert's proposal was vetoed by another expert (points 2 and 3, cycle of R1 and R3 activities in the fourth quarter, Com/Str action context).

The situation only changed when a new structuring approach was proposed and accepted (point 4, R5 activity, Com/Str context, fourth quarter). The points of view,

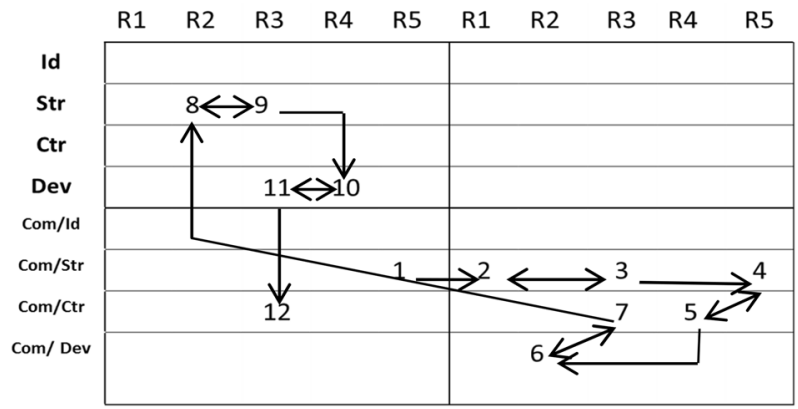

Fig. 11 An example of two basic DA processes in sequence 
which the experts expressed in relation to their knowledge of the field, were organised in a draft MC model that synthesised the proposed judgements in relation to the monitoring process and some possible future decisions. The model was used to elaborate a shared and formal language that involved the experts and the other participants (the actors in the table). Each different interpretation was discussed and only shared elements were included in the model (points 5 and 4, shift from Com/Str to Com/Ctr and vice versa, cycle of the R4 and R5 activities). Some elements, which had been acquired during the monitoring process (data, interviews, critical events and their motivations, evolutions of the funded project or the funding process, and so on), were then analysed and used to express hypotheses, i.e. a set of formulations of how the monitoring results could be used to make a decision. A collective action of Development was facilitated by the R2 activities (point 6 in the fourth quarter), which were used to organise data from the monitoring process as possible results. A shift to the Com/Ctr context and to the R3 activities was required to achieve a collective testing of each hypothesis (point 7).

In the end, another basic DA process, Model structuring and method application was activated (points 8-12). Thus, the models and results of an MC method application were used not only to produce improvement proposals but also to validate the monitoring database and to propose a reference procedure for future monitoring processes and decision activities.

\section{Conclusions}

Practitioners have perceived that only appropriate behaviour for a specific kind of decision process and organisation can facilitate decision aiding in a real situation. However, learning from past interventions is difficult without a logical framework that facilitates documentation and analysis. Young DA analysts cannot use experience and need tools to understand how a good perception of the main complexities of a problem and decision system can orient and guide their actions and why. Organisational change problems need tools that describe how an agile logic of iterative and incremental development of knowledge, with the direct involvement of the actors in a decision process, can be effective and no longer than a very quick approach of problem solving when the problem is not so clear.

For these reasons, a logical framework was proposed to better describe and explain how an analyst behaves or should behave, in complex situations, and which factors mainly influence the time, efforts and results of an intervention. A map, a visualisation tool that synthesises the path of an analyst in a DA process and the prevailing nature of activities and interactions, allows the analysis and comparison of DA processes, which appear as synthetic profiles on a map, and the identification of three typological DA processes as "basic" situations, or "modules" that can be combined to describe a particularly difficult DA process. Figure 12 synthetically describes the basic DA processes by means of the quarter where the process mainly develops (the darkest), the grey quarters that are occasionally used and the white quarter that is not usually used. 


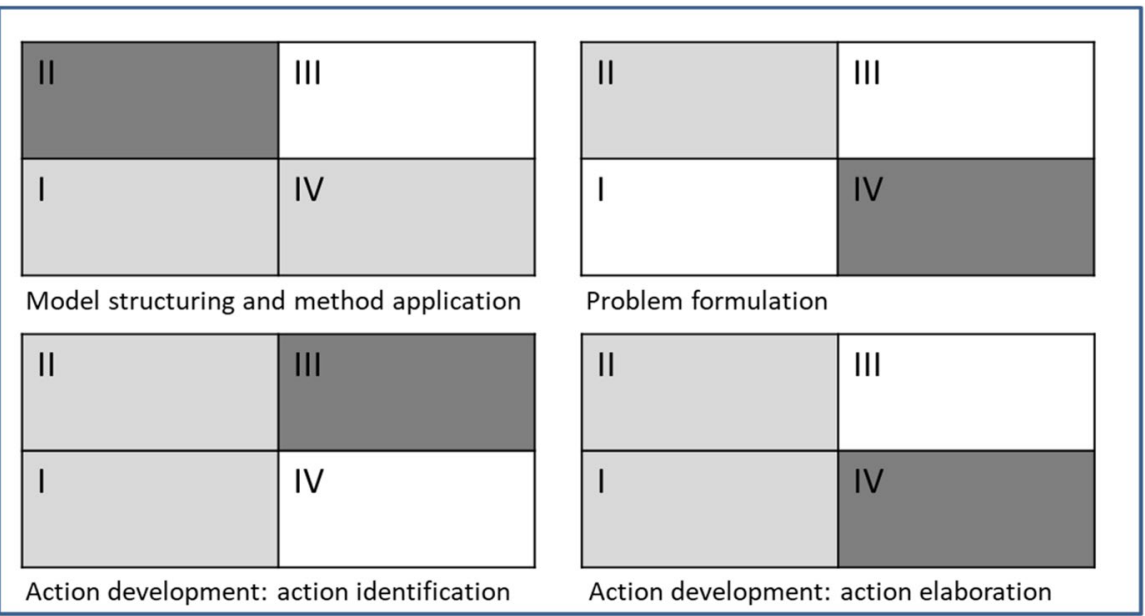

Fig. 12 Logical representation of the DA processes and their main feature

The map and typologies are suitable for an analysis that, after a DA intervention, involves learning from the past, or which, during a very difficult DA path, needs a shared and explicative communication space, to clarify the situation and define a new DA strategy.

The list of possible typologies is not exhaustive, but it can stimulate new analyses of cases and the proposal of new typologies. The basic DA situations can be described, put in relation to factors of complexity and used as guidelines for novice DA analysts. A test of the "legibility" of these typologies (comprehension of the main characteristics of a basic situation and immediate understanding of the complexity factors and their impact on the analyst's behaviour) produced positive reactions in experienced DA analysts, but a limited comprehension in the novices, for example only in relation to the specific typology that a novice DA analyst knows directly.

Some new cases, presented as examples of DA processes, could improve the young analyst comprehension. The cases should be related to different typologies and each one should present how the adopted approach can deal with a specific complexity factor. A future analysis should further study the dynamic factors described in (Mintzberg et al 1976), and above all the failure cycles. The reasons for these cycles have to be analysed in true DA processes to obtain more knowledge and improve some control activities, which should reduce the negative impact of a very long intervention, but at the same time preserve the positive impact of a failure analysis on the individual and collective learning processes.

The map that was proposed to describe any specific DA path is also useful to document and compare different situations, but it should be improved to transparently include and underline the complexity factors that describe the nature and complexity of specific DA interventions for students, practitioners, actors and decision-makers. The logical and simple profiles in Fig. $2 \mathrm{a}$ and $\mathrm{b}$ can be considered a first proposal, because they synthesise the most evident differences in the 
typologies, by means of very simple images. The detailed maps should be made more self-explanatory. I involved some DA analysts in a test of the communicative potentialities of the map and their points of view will be used to make the detailed map a better tool.

Certain elements of the expertise that has been acquired from direct DA experiences in complex decision situations have confirmed that MCDA shows a good adaptability "to the empiric behaviour of decision makers" (Munda 1993) and a clear orientation towards problem solving situations, as defined in (Luoma 2016), that is, decision making non-recurring situations or situations that recur in a novel way. Interactive procedures, which involve the actors in a decision aid process (at least an analyst and a client) and some knowledge sources, are always activated in MCDA interventions (Vanderpooten 2002). However, a large variety of tools can be used to help the analyst in his/her individual work (in the second quarter of the map) and only a few of them offer actual support in interaction and communication contexts. Therefore, an MC model often becomes a tool which plays an important role in decision aiding, as an evolving system that generates a communication space between an analyst and a decision system (see Landry et al 1996; Genard and Pirlot 2002; Tsoukias 2007). A future detailed analysis of how an intelligent integration of different tools (which may be analytical systems, conceptual and formal models and procedures, but also diagrams, images and sketches) can contribute to facilitating interaction and learning, in relation to the different contexts of action, and to improving DA in practice.

An analysis of the roles, actions and interactions of the DA process actors is essential to distinguish between the risky behaviour of an analyst and behaviour that can improve the effectiveness of a DA process. The analyst's behaviour in the DA process typologies is linked to certain characteristics of the decision problem, system and process that should be investigated at the start of any DA intervention. They are essential to identify the action space and its resources and constraints, to adopt a consistent approach and to activate contexts of action that are aimed at reducing complexity, controlling uncertainty and improving the robustness of the overall intervention and its results, at both an organisational and an operational level.

For these reasons, the DA analysts who were involved in the improvement of the communicative role of the map were sent an invitation to send me feedback on the structural components of the framework, not only to validate their consistency and completeness, but also to operationally use the framework (and the map, or an improved version of the map) in a research project aimed at communicating our expertise to young DA analysts by means of a structured sequence of DA cases.

Each DA analyst was asked to use the framework to recognise the typologies of personal DA interventions and to underline the main complexity elements (in relation to the decision system, actor network, structuring level of the problem situation, unavailable resources, multiplicity and interdependency level of the problem issues etc.) and the behaviour they adopted to deal with them. The idea was to identify a set of DA cases and combine them in a structured system that includes all the different DA typologies and at least one DA process description for each main complexity factor. 
Funding Open access funding provided by Politecnico di Torino within the CRUI-CARE Agreement.

Open Access This article is licensed under a Creative Commons Attribution 4.0 International License, which permits use, sharing, adaptation, distribution and reproduction in any medium or format, as long as you give appropriate credit to the original author(s) and the source, provide a link to the Creative Commons licence, and indicate if changes were made. The images or other third party material in this article are included in the article's Creative Commons licence, unless indicated otherwise in a credit line to the material. If material is not included in the article's Creative Commons licence and your intended use is not permitted by statutory regulation or exceeds the permitted use, you will need to obtain permission directly from the copyright holder. To view a copy of this licence, visit http://creativecommons.org/licen ses/by/4.0/.

\section{References}

Ackermann F (2011) Getting "messy" with problems: the challenges of teaching "soft" OR. Informs T Edu 12:55-64

Balestra G, Norese MF, Knaflitz M (2001) Model structuring to assess the progression of a muscular dystrophy. In: Colorni A, Parruccini M, Roy B (eds) A-MCD-A - Aide Multicritère à la Décision (Multiple Criteria Decision Aiding). European Commission Joint Research Centre EUR Report, Luxembourg, pp 31-46

Belton V, Pictet J (2002) Talking about the practice of MCDA. In: Boyssou D, Jacquet-Lagrèze E, Perny P, Slowinski R, Vanderpooten D, Vincke Ph (eds) Aiding decisions with multiple criteria: essays in honour of Bernard Roy. Kluwer Academic, Dordrecht, pp 71-88

Belton V, Stewart TJ (2002) Multiple criteria decision analysis: an integrated approach. Kluwer Academic, Dordrecht

Bouyssou D, Marchant T, Pirlot M, Perny P, Tsoukiàs A, Vincke Ph (2000) The purpose of Evaluation and Decision Models: A Critical Perspective. Springer Science \& Business Media, New York

Bowen K (1983) An experiment in problem formulation. J Oper Res Soc 34:685-694

Cavallo A, Norese MF (2001) Slope instability and erosion: hazard evaluation through the integration of GIS and Multicriteria Analysis. Informatica 12:25-44

Colorni A, Tsoukiàs A (2018) What is a decision problem? designing alternatives. In: Matsatsinis N, Grigoroudis E (eds) Preference disaggregation in Multiple Criteria Decision Analysis. Springer Verlag, Berlin, pp 1-15

de Montgolfier J, Bertier P (1978) Approche Multicritère des problèmes de décision. Editions Hommes et Techniques, Paris

Franco LA, Montibeller G (2010) Facilitated modelling in operational research. Eur J Opl Res 205:489-500

Friend J (1989) The strategic choice approach. In: Rosenhead J (ed) Rational analysis for a problematic world: problem structuring methods for complexity, uncertainty and conflict. Wiley, Chichester, pp 121-158

Genard J-L, Pirlot M (2002) Multi-Criteria Decision-Aid in a philosophical perspective. In: Boyssou D, Jacquet-Lagrèze E, Perny $\mathrm{P}$, Slowinski R, Vanderpooten D, Vincke Ph (eds) Aiding decisions with multiple criteria: essays in honour of Bernard Roy. Kluwer Academic, Dordrecht, pp 89-117

Jacquet-Lagrèze E, Roy B, Moscarola J, Hirsh G (1978) Description d'un processus de decision Quelques concepts. Cahier du LAMSADE 13

Landry M, Banville C, Oral M (1996) Model legitimation in Operations Research. Eur J Opl Res 92:443-457

Landry M, Malouin JL, Oral M (1983) Model validation in Operations Research. Eur J Opl Res 17:207-220

Langley A, Mintzberg H, Pitcher P, Posada E, Saint-Macary J (1995) Opening up decision making:the view from the black stool. Organ Sci 6:260-279

Luoma J (2016) Model-based organizational decision making: a behavioural lens. Eur J Opl Res 249:816-826 
Marttunen M, Lienert J, Belton V (2017) Structuring problems for Multi-Criteria Decision Analysis in practice: A literature review of method combinations. Eur J Opl Res 263:1-17

Mintzberg H, Raisinghani D, Theoret A (1976) The structure of the unstructured decision process. Adm Sci Q 21:246-276

Montagna F, Norese MF (2008) A hybrid approach to model design and development processes and evaluate innovation opportunities. Int J Manuf Technol Manage 14:379-395

Munda G (1993) Multiple-Criteria Decision Aid : some epistemological considerations. J Multi-Crit Decis Anal 2:41-55

Norese MF (1995) MACRAME: A problem formulation and model structuring assistant in multiactorial contexts. Eur J Opl Res 84:25-34

Norese MF (1996) A process perspective and multicriteria approach in Decision-Aiding contexts. J Multi-Crit Decis Anal 5:133-144

Norese MF (2016b) A model-based process to improve robustness in Multi Criteria Decision Aiding interventions. J Multi-Crit Decis Anal 23:183-196

Norese MF, Carbone V (2014) An application of ELECTRE Tri to support innovation. J Multi-Crit Decis Anal 21:77-93

Norese MF, Liguigli E, Novello C (2013) Integrated use of mathematical programming and multiple criteria methods in engineering design processes. Int J Multicriteria Decision making 3:346-361

Norese MF, Novello C, Salassa F (2015) An integrated system to acquire knowledge and support decisions in complex innovation design processes. J Org Comp Elect Com 25:194-212

Norese MF, Ostanello A (1989) Identification and Development of Alternatives: Introduction to the recognition of process typologies. In: Lockett AG, Islei G (eds) Improving Decision Making in Organisations. Springer-Verlag, Heidelberg, pp 112-123

Norese MF, Salassa F (2014) Structuring fragmented knowledge: A Case Study. Knowl Man Res Pract 12:454-463

Norese MF, Scarelli A (2016) Decision aiding in public policy generation and implementation: a multicriteria approach to evaluate territorial resilience. Territorio Italia 2:71-90

Norese MF, Torta V (2014) A decision support system in order to facilitate new financing actions in the public sector. Territorio Italia 2:85-100

Norese MF, Viale S (2002) A multi-profile sorting procedure in the public administration. Eur J Opl Res 138:365-379

Norese MF (2016a) Decision aid in public administration: from evidence-based decision making to organizational learning. In: Zopounidis C, Doumpos M (eds) Multiple Criteria Decision Making: Applications in Management and Engineering. Springer, Heidelberg, pp 1-29

Norese MF (2010) How to support decisions and guarantee robustness in Multi Criteria Decision Aid when the preference system is not "accessible". In: Zopounidis C, Doumpos M, Matsatsinis NF, Grigoroudis E (eds) Multiple criteria decision aiding. Nova Science Publishers, New York, pp $1-16$

Norese MF, Mustafa A, Scarelli A (2016) New frontiers for MCDA: from several indicators to structured models and decision aid processes, Newsletter of the European Working Group "Multiple Criteria Decision Aiding" Series 3, 34 Fall pp 1-8

Nutt PC (1993) The identification of solution ideas during organizational decision making. Manage Sci 39:1071-1085

Ormerod RJ (2014) The mangle of OR practice: towards more informative case studies of 'technical'projects. J Oper Res Soc 65:1245-1260

Ormerod RJ (2018) The logic and methods of OR consulting practice: towards a foundational view. J Oper Res Soc 69:1357-1378

Ostanello A (1990) Action evaluation and action structuring: different decision aid situations reviewed through two actual cases. In: Bana e Costa CA (ed) Readings in Multiple Criteria Decision Aid. Springer-Verlag, Heidelberg, pp 36-57

Ostanello A (1996) Understanding and structuring complex problems within organizational contexts. CC-AI: the journal for the integrated study of artificial intelligence cognitive science and applied epistemology 13:29-54

Rosenhead J (1996) What's the Problem? An Introduction to Problem Structuring Methods. Interfaces 26:117-131

Rosenhead J (2006) The past, the present and the future of problem structuring methods. J Oper Res Soc 57:759-765 
Rosenhead J (1989) Rational analysis for a problematic world: problem structuring methods for complexity, uncertainty and conflict (ed.), Wiley, Chichester

Rosenhead J, Mingers J (2001) Rational Analysis for a Problematic World Revisited, Problem Structuring Methods for Complexity, Uncertainty and Conflict (eds.), Wiley, Chichester

Roy B (1996) Multicriteria methodology for decision aiding. Kluwer Academic, Dordrecht

Roy B, Vanderpooten D (1996) The European school of MCDA: Emergence, basic features and current works. J Multi Crit Decis Anal 5:22-38

Roy B (1976) A conceptual framework for a normative theory of "decision-aid". Cahier du LAMSADE 3

Simon HA (1960) The New Science of Management Decision. Harper and Brothers, New York

Simon HA (1991) Bounded Rationality and Organisational Learning. Organ Sci 2:125-139

Smith CM, Shaw D (2019) The characteristics of problem structuring methods: A literature review. Eur J Opl Res 274:403-416

Tsoukiàs A (2007) On the concept of decision aiding process: An operational perspective. Ann Oper Res 154:3-27

Vanderpooten D (2002) Modelling in decision aiding. In: Boyssou D, Jacquet-Lagrèze E, Perny P, Slowinski R, Vanderpooten D, Vincke Ph (eds) Aiding decisions with multiple criteria: essays in honour of Bernard Roy. Kluwer Academic, Dordrecht, pp 195-210

White L (2016) Behavioural operational research: Towards a framework for understanting behaviour in OR interventions. Eur J Opl Res 249:827-841

Witte E (1972) Field research on complex decision-making processes - The phase theorem. Int Stud Manag Organ 2:156-182

Publisher's Note Springer Nature remains neutral with regard to jurisdictional claims in published maps and institutional affiliations. 